\title{
Changes in heart rate and blood lactate concentration during karate kata competition
}

\author{
Penov R. ${ }^{1 \mathrm{ABE}}$, Petrov L. ${ }^{1 \mathrm{ABCD}}$, Kolimechkov S. ${ }^{2 \mathrm{ACD}}$ \\ ${ }^{1}$ National Sports Academy, Sofia, Bulgaria \\ ${ }^{2} S T K$ Sport, London, United Kingdom
}

Authors' Contribution: A - Study design; B - Data collection; C - Statistical analysis; D - Manuscript Preparation; E - Funds Collection

\begin{tabular}{|c|c|}
\hline \multicolumn{2}{|l|}{ Abstract } \\
\hline Purpose: & $\begin{array}{l}\text { Karate is going to take part in the Olympic games, for the first time in Tokyo } 2020 \text {. The aim of this study } \\
\text { was to analyse the changes in heart rate (HR) and blood lactate concentration of karate practitioners } \\
\text { performing different katas in competitive conditions. }\end{array}$ \\
\hline Material: & $\begin{array}{l}\text { This study consisted of five elite male athletes ( } 26.80 \pm 5.97 \text { years), members of the Bulgarian national team } \\
\text { in Shotokan karate, competing in the kata discipline. The study was conducted in competitive conditions } \\
\text { during national competitions, in which three katas were performed by each of the competitors. Capillary } \\
\text { blood lactate concentration (La) was determined at rest and after each kata. Heart rate (HR) was registered } \\
\text { and physical activity was monitored by using three-dimensional accelerometers. }\end{array}$ \\
\hline Results: & $\begin{array}{l}\text { The mean La increased progressively after each following kata: } 1.4 \pm 0.32 \mathrm{mmol} / \mathrm{L} \text { at rest, } 4.7 \pm 1.91 \mathrm{mmol} / \mathrm{L} \\
\text { after the first, } 6.8 \pm 2.59 \mathrm{mmol} / \mathrm{L} \text { after the second, and } 7.1 \pm 2.35 \mathrm{mmol} / \mathrm{L} \text { after the third kata. This increase } \\
\text { was significant after the second ( } \mathrm{p}<0.05 \text { ) and third }(\mathrm{p}<0.01) \text { kata, in comparison with the registered La } \\
\text { at rest. The mean HR values reached } 179 \pm 11.55 \mathrm{bpm} \text { during the first, } 180 \pm 11.63 \mathrm{bpm} \text { during the second, } \\
\text { and } 181.5 \pm 15.44 \mathrm{bpm} \text { during the third kata. Notwithstanding the differences in the physiological and } \\
\text { biochemical parameters of participants No1 and No2, the mean physical activity units (FAU) were similar: } \\
120165 \mathrm{FAU} \text { after the first kata, and } 111805 \mathrm{FAU} \text { after the second vs } 126618 \mathrm{FAU} \text { after the first, and } 89544 \\
\text { FAU after the second kata, respectively. The explanation of these different observations is probably due } \\
\text { to the style of the competitors. For instance, according to his coaches, participant No } 2 \text { is performing kata } \\
\text { with a higher level of tension in those muscle groups which are not necessarily involved in maintaining } \\
\text { the posture and executing the moves. In contrast, the lower La values observed in participant No1, in } \\
\text { comparison with the other competitors, were probably due to a more relaxed performance with smaller } \\
\text { amplitude of the moves. Participants No4 and No5 from our study showed moderate La values after each } \\
\text { of the three katas. According to their coaches, those competitors perform kata with optimal speed and } \\
\text { amplitude, without too high a level of tension in the muscle groups which are not involved in the moves. }\end{array}$ \\
\hline Conclusions: & $\begin{array}{l}\text { The La appeared to be a more informative parameter than heart rate, and the moderate increase of the } \\
\text { La values }(4-6 \mathrm{mmol} / \mathrm{L}) \text { indicated optimal muscle tension and amplitude of moves when performing } \\
\text { katas in competitive conditions. Further research is needed to determine the optimal La levels for the } \\
\text { performance of different katas. }\end{array}$ \\
\hline Keywor & \\
\hline
\end{tabular}

\section{Glossary}

Kumite - karate competitive discipline in which two athletes perform various kicking, punching and blocking techniques towards each other with maximum control in order to score points and win the fight. The fights are ritualistic and noncontact [1].

Kata - karate competitive discipline in which each athlete performs various katas (prescribed sequences of karate techniques) [2].

Performance - (noun) the level at which an athlete is carrying out their activity, either in relation to others or in relation to personal goals and standards [2].

Technique - (noun) a way of performing an action [2].

\section{Introduction}

Karate is a martial art, which was developed in Japan, and has two competitive disciplines: kumite and kata [3]. Kata is comprised of a predetermined sequence of techniques, which represent actual fights against imaginary opponents, and the practitioners in this discipline are judged on the execution of their technique, rhythm, power and expressiveness of movements [4]. The performance in kata incorporates different types of kata (c) Penov R., Petrov P., Kolimechkov S., 2020 doi:10.15561/26649837.2020.0306 techniques. During competitions, the karate practitioners perform fixed kata styles (katas) that have a different duration for every kata performed [3].

There are twenty-six fixed katas in Shotokan karate: Heinan Shodan, Heian Nidan, Heian Sandan, Heian Yondan, Heian Godan, Tekki Shodan, Bassai Dai, Kanku Dai, Enpi, Jion, Hangetsu, Kanku Sho, Tekki Nidan, Bassai Sho, Nijushiho, Jitte, Tekki Sandan, Unsu, Sochin, Gankaku, Meikyo, Wankan, Chinte, Jiin, Gojushiho Sho, Gojushiho Dai. The first five kata styles (Heian) are more 
basic, and, therefore, they are the first learnt by karate practitioners. Each kata can be used in competitions in accordance with the athlete's ability and the rank of the competition [5].

It is recommended that karate practitioners should perform more specific training, plyometric exercises, and interval training in order to increase the ability to buffer acid muscle and blood concentrations [6]. The training and testing processes have to be very similar to competitive conditions for achieving high performance results in karate. Different specific karate tests, such as the Karate Specific Aerobic Test [7, 8], which has been reported to be valid and reliable field test for assessing karateka's aerobic fitness [9, 10], and programmed karate models $[11,12]$ have been developed. However, those studies are mostly concerned with karate competitors in the kumite discipline. The articles which analysed the physiological and biochemical changes in karate practitioners during karate kata competitions in the scientific literature are scarce, and the fact that this sport is going to be part of the Olympic games in Tokyo 2020 [13, 14], is increasing the interest in new studies in this area. Some authors reported heart rate responses $[15,16]$ or heart rate and oxygen uptake responses [17] of karate practitioners performing kata. The energy supply in karate kata comes from both anaerobic alactic and aerobic systems [18]. However, it is very difficult to determine visually the muscle efforts, as well as the energy expenditure of karate practitioners, while they perform one or another kata. Therefore, the assessment of physiological and biochemical changes in the body while performing kata can provide information on the functional status of the athlete, and help determine work capacity and level of training.

The aim of this study was to analyse the changes in heart rate and blood lactate concentration of karate practitioners performing different katas in competitive conditions, and compare the physiological and biochemical changes in the parameters of individual competitors in different katas.

\section{Material and methods}

\section{Participants}

This study consisted of five male competitors in karate kata from the Bulgarian national team. All participants possess black belts, and had a mean age of $26.80 \pm 5.97$ years, with an average sports experience in karate of 16.60 \pm 7.27 years. Body weight and height were measured, and body mass index (BMI) was calculated as body weight [kg] divided by body height [m] squared.

The participants in this study were informed about its purpose, and signed informed consents were obtained, in accordance with the requirements of the Declaration of Helsinki for Human Research [19].

Procedure

Three of the participants were tested during the 2018 National Karate Championships, and the other two at the 2018 Bulgarian National Cup. All of them qualified for the finals and won medals. The participants performed three katas at the competitions, and the average time between the end of the first kata and the beginning of the second was around 25 minutes, and the time between the second and the third was around $20 \mathrm{~min}$.

Heart rate (HR) and Physical activity

Heart rate (HR) was registered with the Sigma heart rate monitor, and recorded with the 'beat by beat' telemetric system, called TEMEO, produced by the Security Solutions Institute, Bulgaria [20]. The telemetric system also recorded the average accelerations in three orthogonal axes (X, Y and Z) using a built-in threedimensional accelerometer. In order to assess the physical activity during the kata performance, the total average acceleration vector $(\mathrm{AccV})$ from the three axes was taken in periods of 100 milliseconds, and this data was summed during the time of performance of each kata in order to be obtained as physical activity units (FAU).

Lactate concentration ( $\mathrm{La})$

Capillary blood was taken from the pendant of the athlete's ear before the first kata, and 5 min after the end of each kata, and the lactate concentration was determined using LactatePro 2 LT-1730, produced by the Japanese company, Arkray Global Business Inc [21].

\section{Statistical analysis}

The statistical analyses were conducted with Excel 2010 spreadsheets and GraphPad Prism 7.04 Software. Statistically significant differences between the average values were evaluated at $p<0.05$, by using the non-parametric Friedman test with Dunn's multiple comparisons post hoc test. The data in the text and the tables are presented as mean \pm standard deviation (SD), and in the figures are presented as mean $\pm \mathrm{SE}$.

\section{Results}

The anthropometric parameters, each athlete's sport experience in karate, as well as the best sports achievements from national and international competitions of all participants in this study, are presented in Table 1.

The names of the katas which were performed by each athlete at the competitions, and their duration, are presented in Table 2. The average time of the kata performances after the first stage of the competitions was 1:08 0:02 min. The shortest performance was 1:05 min, and the longest was 1:13 min.

The individual values of the blood lactate concentration (La) after warm-up, first, second and third kata, in addition to their individual mean values from the three katas, are presented in Table 3. The mean La after the warm-up was $1.4 \pm 0.32 \mathrm{mmol} / \mathrm{L}$, and progressively increased after each following kata: $4.7 \pm 1.91 \mathrm{mmol} / \mathrm{L}$ after the first, $6.8 \pm$ $2.59 \mathrm{mmol} / \mathrm{L}$ after the second, and $7.1 \pm 2.35 \mathrm{mmol} / \mathrm{L}$ after the third kata.

A statistically significant increase in the blood lactate concentration was found after the second $(p<0.05)$ and third $(\mathrm{p}<0.01) \mathrm{kata}$, in comparison with the registered $\mathrm{La}$ at rest (after the warm-up). However, the increase in lactate concentration after the third kata vs the second one is not significant.

Heart rate and physical activity were monitored throughout the performance of each kata, and the individual heart rate before the first kata varied from 
Table 1. Anthropometric parameters, sports experience and main achievements of the karate practitioners.

\begin{tabular}{llllllll|}
\hline No & $\begin{array}{l}\text { Age } \\
\text { [years] }\end{array}$ & $\begin{array}{l}\text { Experience } \\
\text { [years] }\end{array}$ & Dan & $\begin{array}{l}\text { Competition, } \\
\text { place/frequency }\end{array}$ & $\begin{array}{l}\text { Height } \\
\text { [cm] }\end{array}$ & $\begin{array}{l}\text { Weight } \\
{[\mathrm{kg}]}\end{array}$ & $\begin{array}{l}\text { BMI } \\
{\left[\mathrm{kg} . \mathrm{m}^{-2}\right]}\end{array}$ \\
\hline 1 & 20 & 6 & 1 & IST, 3/1 & 183.0 & 80.0 & 23.9 \\
2 & 23 & 18 & 2 & WC3/1; EC3/1; NC1/1 & 165.0 & 73.0 & 26.8 \\
3 & 25 & 13 & 1 & NC 1/3 & 175.0 & 64.0 & 20.9 \\
4 & 32 & 22 & 2 & WC3/1; EC3/1; NC2/4 & 171.5 & 64.2 & 21.8 \\
5 & 34 & 24 & 3 & WC 3/1; NC 1/5 & 170.0 & 74.0 & 25.6 \\
Average & 26.80 & 16.60 & & & 172.90 & 71.04 & 23.81 \\
SD & 5.97 & 7.27 & & & 6.69 & 6.88 & 2.48 \\
\hline
\end{tabular}

WC - World SKDUN Championships; EC - European SKDUN Championships; NC - National SKDUN Championships; IST - International Shotokan Tournaments

Table 2. Name and duration of each kata performed by the participants

\begin{tabular}{lllllll}
\hline No & Time 1st & mm:ss & Time 2nd & mm:ss & Time 3th & mm:ss \\
\hline 1 & Jion & $01: 05$ & Enpi & $01: 02$ & Gojushiho-sho & $01: 47$ \\
2 & Jion & $01: 08$ & Enpi & $00: 52$ & Kanku-dai & $01: 33$ \\
3 & Jion & $01: 08$ & Enpi & $01: 01$ & Gojushiho-sho & $01: 22$ \\
4 & Bassai-dai & $01: 13$ & Jion & $01: 19$ & Sochin & $00: 56$ \\
5 & Kanku-dai & $01: 09$ & Enpi & $01: 21$ & Sochin & $00: 59$ \\
\hline
\end{tabular}

Table 3. Individual and mean values of the lactate concentration (La) after the warm-up (Rest), first, second and third katas during the competitions $(n=5)$.

\begin{tabular}{llllll|}
\hline No & Rest & La After 1st & La After 2nd & La After 3th & $\begin{array}{l}\text { Average La after } \mathbf{1}^{\text {st }} \mathbf{2}^{\text {nd }} \text { and } \\
\mathbf{3}^{\text {rd }}\end{array}$ \\
\hline & mmol/L & mmol/L & mmol/L & mmol/L & mmol/L \\
1 & 1.2 & 3.0 & 3.0 & 4.3 & $3.4 \pm 0.75$ \\
2 & 1.3 & 7.8 & 9.8 & 8.1 & $8.6 \pm 1.08 \#$ \\
3 & 1.1 & 4.5 & 6.6 & 10.5 & $7.2 \pm 3.04$ \\
4 & 1.9 & 3.3 & 6.1 & 6.7 & $5.4 \pm 1.81$ \\
5 & 1.5 & 5.0 & 8.5 & 5.9 & $6.5 \pm 1.82$ \\
Average & $\mathbf{1 . 4}$ & $\mathbf{4 . 7}$ & $\mathbf{6 . 8}$ & $\mathbf{7 . 1 * *}$ & \\
SD & $\mathbf{0 . 3 2}$ & $\mathbf{1 . 9 1}$ & $\mathbf{2 . 5 9}$ & $\mathbf{2 . 3 5}$ & \\
SE & 0.14 & 0.85 & 1.16 & 1.05 & \\
\hline
\end{tabular}

* $-\mathrm{p}<0.05$ vs La at Rest; ** $-\mathrm{p}<0.01$ vs La at Rest; \#-p<0. 05 vs the mean La of the three katas performed by participant No1.

$84 \mathrm{bpm}$ (participant No2) to 108 (participant No4). The heart rate increased in all competitors at the end of the performance of each kata, and the highest registered values were $189 \mathrm{bpm}$ (participant No1 after the first kata) and $194 \mathrm{bpm}$ (participant No3 after the second kata). During the rest periods between the performances, heart rate decreased and varied between 84 and $116 \mathrm{bpm}$. The heart rate and physical activity from two of the tested karate practitioners (No1 and No2) are presented in Figure 1.

The mean HR values of the karate practitioners showed a big increase while performing katas, reaching
$179 \pm 11.55 \mathrm{bpm}$ during the first, $180 \pm 11.63 \mathrm{bpm}$ during the second, and $181.5 \pm 15.44 \mathrm{bpm}$ during the third kata (Figure 2). Heart rate decreased during the breaks between each kata $(102.3 \pm 13.02 \mathrm{bpm}$ after the first, $105 \pm 10.80$ bpm after the second, and $105.5 \pm 5.92 \mathrm{bpm}$ after the third kata) and was close to the initial $96.3 \pm 10.01 \mathrm{bpm}$.

\section{Discussion}

Elite senior male competitors in karate kata $(n=12)$ from Serbia were reported to have a mean height of 174.3 $\pm 5.5 \mathrm{~cm}$, weight $70.5 \pm 5.0 \mathrm{~kg}$, and BMI $23.2 \pm 1.8 \mathrm{~kg} . \mathrm{m}^{-2}$ [22]. These anthropometric results are very close to the 


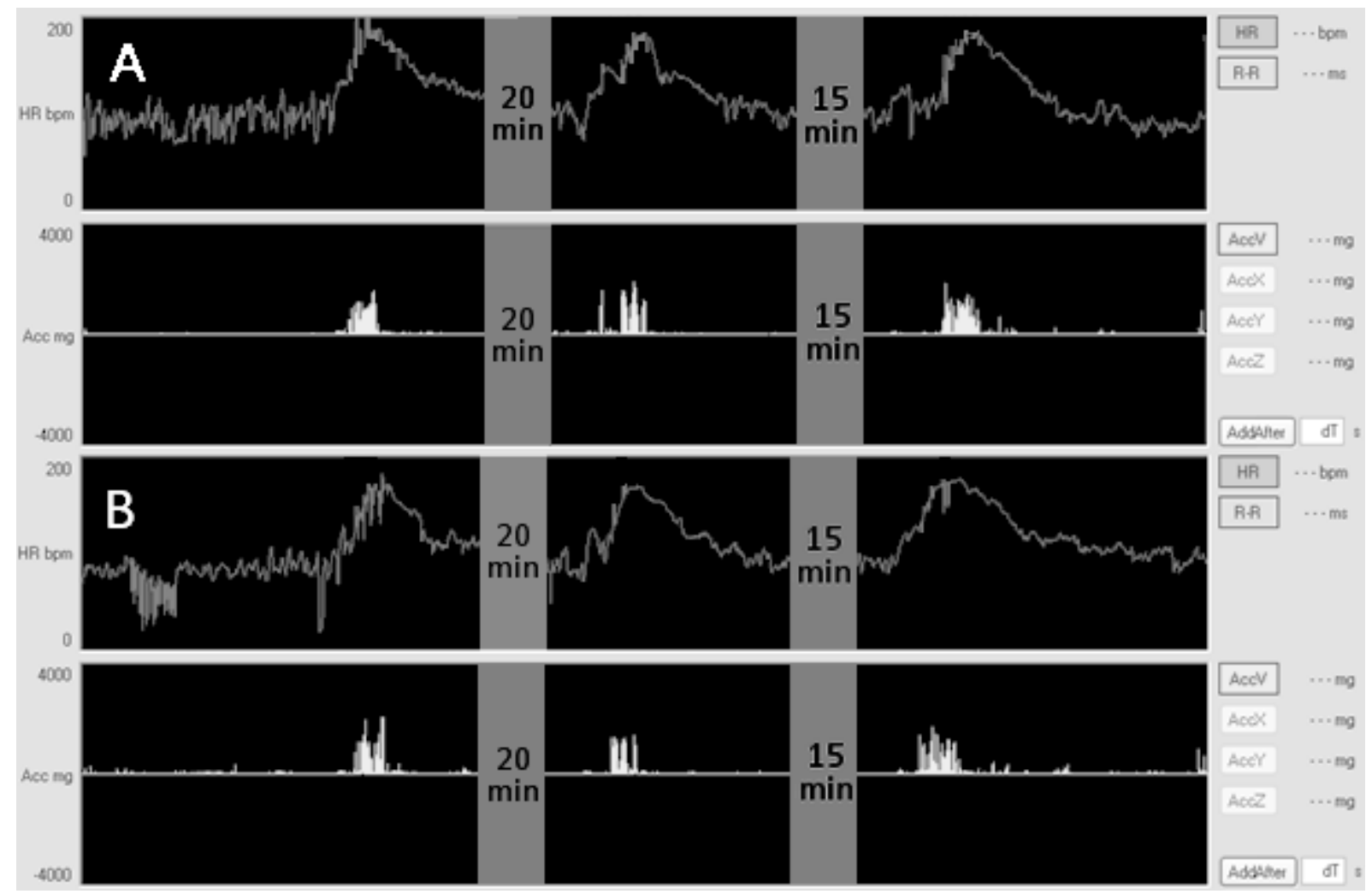

Figure 1. The heart rate (HR) and physical activity data presented as total average acceleration from the threedimensional accelerometer (AccV) of karate practitioners No1 (A) and No2 (B) during the performance of 3 katas.

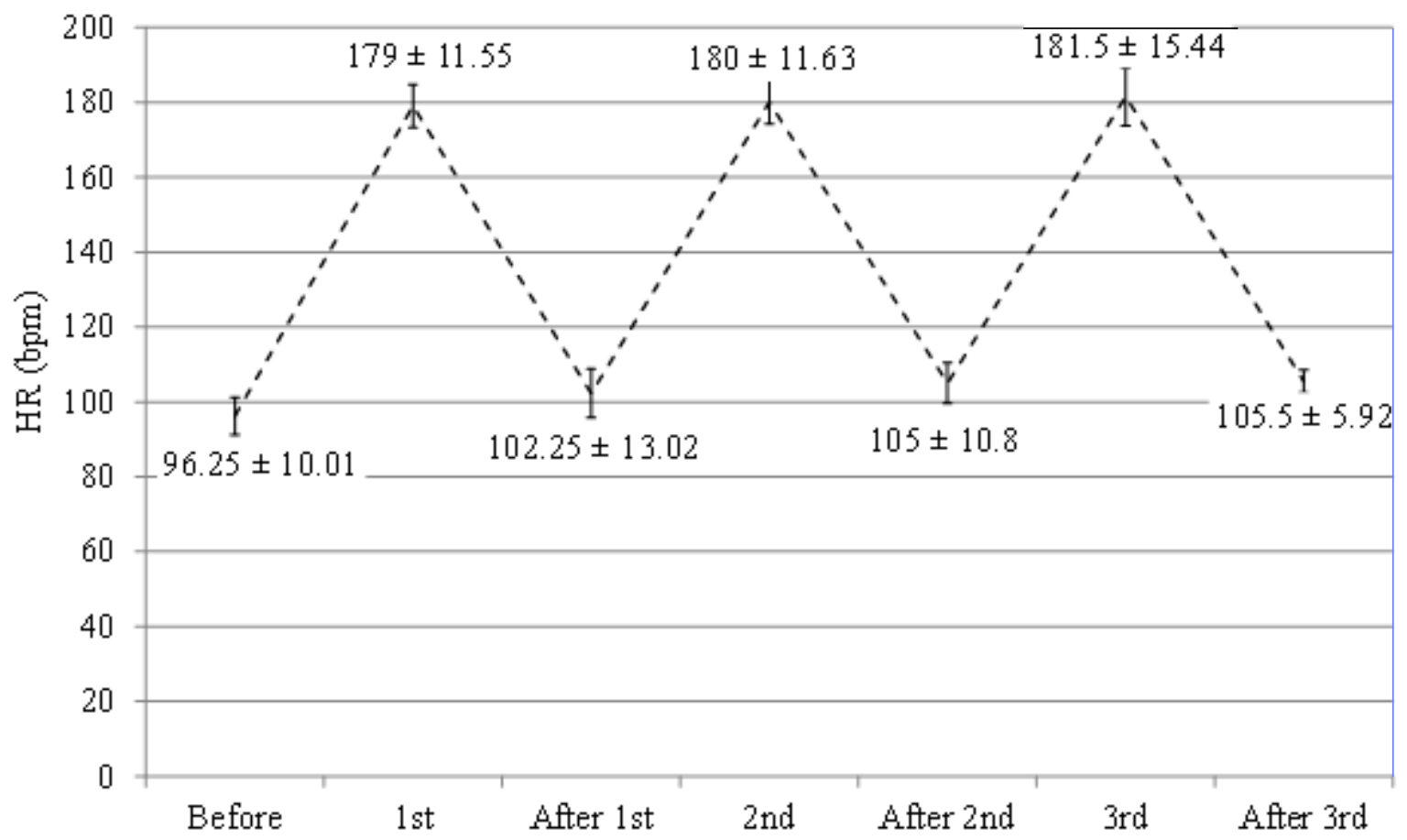

Figure 2. Mean heart rate (HR) values of the karate practitioners before and after the performance of each kata. 
findings from our study: $172.9 \pm 6.7 \mathrm{~cm}, 71.0 \pm 6.9 \mathrm{~kg}$, $23.8 \pm 2.5 \mathrm{~kg} . \mathrm{m}^{-2}$, respectively.

In a study of three world champions in karate kata from Italy, the mean blood lactate concentration (La) was $4.8 \mathrm{mmol} / \mathrm{L}$ after performing Gankaku kata in training conditions [4]. Those values are very close to the ones in our study after performing the first kata $(4.7 \mathrm{mmol} / \mathrm{L})$. However, the individual La values of participant No2 in our study were considerably higher after the performance of each of the three katas $(7.8 \mathrm{mmol} / \mathrm{L}, 9.8 \mathrm{mmol} / \mathrm{L}$, and $8.1 \mathrm{mmol} / \mathrm{L}$ ) in comparison with the other competitors. Similar values were registered only at the end of the third kata (Kanku-dai) in participant No $3(10.5 \mathrm{mmol} / \mathrm{L})$, but the duration of Kanku-day kata from participant No3 was 1.5 times longer than the other katas. Although participant No2 had the highest La values, his heart rate was lower than the other athletes, both during the kata performance (170 bmp) and during the recovery periods (around 90 bmp). Notwithstanding the differences in the physiological and biochemical parameters of participants No1 and No2, the mean physical activity units (FAU) were similar: 120 165 FAU after the first kata, and 111805 FAU after the second vs 126618 FAU after the first, and 89544 FAU after the second kata, respectively. The explanation of these different observations is probably due to the style of the competitors. For instance, according to his coaches, participant No2 is performing kata with a higher level of tension in those muscle groups which are not necessarily involved in maintaining the posture and executing the moves. In contrast, the lower La values observed in participant No1, in comparison with the other competitors, were probably due to a more relaxed performance with smaller amplitude of the moves. According to Bussweiler and Hartmann, the style variations and the type of kata in karate lead to different levels of tension in muscle mass, especially in the lower body, due to the variety of stances [18]. Participants No4 and No5 from our study showed moderate La values after each of the three katas.
According to their coaches, those competitors perform kata with optimal speed and amplitude, without too high a level of tension in the muscle groups which are not involved in the moves.

The mean heart rate value in the three world champions in karate kata, from the study already mentioned, was reported to be $150 \mathrm{bpm} \mathrm{[4],} \mathrm{which} \mathrm{is} \mathrm{lower} \mathrm{than} \mathrm{the} \mathrm{one}$ registered in our study for all participants and in all katas. The performance of Gankaku kata by the Italian elite competitors was defined to be of high technical difficulty, and was executed with a lower heart rate than that in our study, but with a similar blood lactate concentration values, which is probably because the Italian athletes performed this kata in training conditions.

In another study, which was also conducted on karate kata practitioners at international level $(\mathrm{n}=3)$, the authors reported an average increase of La by $6.5 \pm 1.3 \mathrm{mmol} / \mathrm{L}$ above resting level after performing Unsu kata during a simulated competition [3]. The mean HRmax during this simulated kata competition was $176 \pm 12.0$. These findings are similar to the ones from our study.

\section{Conclusions}

The blood lactate concentration (La) provided valuable information about the assessment of the performance in karate kata, and it was also shown to be a more informative parameter than heart rate. In our study, the moderate increase of the La values $(4-6 \mathrm{mmol} / \mathrm{L}$ ) indicated optimal muscle tension and amplitude of moves when performing kata in competitive conditions. Further research is needed to determine the optimal La levels for the performance of different katas, both in training and in competitive conditions.

\section{Conflict of interests}

The authors declare that there is no conflict of interests.

\section{References}

1. Budō: The Martial Ways of Japan. Tokyo: The Nippon Budokan Foundation; First Edition; 2009.

2. Dictionary of Sport and Exercise Science. Over 5,000 Terms Clearly Defined. London: A \& B Black; 2006.

3. Doria C, Veicsteinas A, Limonta E, Maggioni MA, Aschieri P, Eusebi F, et al. Energetics of karate (kata and kumite techniques) in top-level athletes. European journal of applied physiology. 2009;107(5):603-10. https://doi.org/10.1007/s00421-009-1154-y

4. Invernizzi PL, Longo S, Scurati R. Analysis of heart rate and lactate concentrations during coordinative tasks: pilot study in karate kata world champions. Sport Sci Health, 2008;3:41-6. https://doi.org/10.1007/s11332-008-0053-7

5. SKDUN. Shotokan Karate Do of United Nations (SKDUN), Rules of karate competition (kumite and kata), May 2018 [Internet]. 2018. [updated 2019; cited 2019 Nov 11]. Available from: https://www.skdun.org/wp-content/ uploads/2018/10/SKDUN-Rule-book-March-2016-withamendments-May-2018.pdf
6. Iide K, Imamura H, Yoshimura Y, Yamashita A, Miyahara $\mathrm{K}$, Miyamoto N, et al. Physiological responses of simulated karate sparring matches in young men and boys. Journal of strength and conditioning research. 2008;22(3):839-44. https://doi.org/10.1519/JSC.0b013e31816a5af6

7. Nunan D. Development of a sports specific aerobic capacity test for karate - a pilot study. Journal of sports science \& medicine. 2006;5(CSSI):47-53.

8. Karate Specific Aerobic Test Software. London, United Kingdom: STK Sport [Internet]. 2020. [updated 2019; cited 2019 Nov 10]. Available from: https://www.stk-sport.co.uk/ shop-karate-aerobic-test-software.html

9. Chaabene H, Hachana Y, Franchini E, Mkaouer B, Montassar M, Chamari K. Reliability and construct validity of the karate-specific aerobic test. Journal of strength and conditioning research. 2012;26(12):3454-60. https://doi.org/10.1519/JSC.0b013e31824eddda

10.Tabben M, Coquart J, Chaabene H, Franchini E, Chamari $\mathrm{K}$, Tourny C. Validity and reliability of new karatespecific aerobic test for karatekas. International journal 
of sports physiology and performance. 2014;9(6):953- 8 . https://doi.org/10.1123/ijspp.2013-0465

11. Alexandrova A, Penov R, Petrov L, Cholakov K, Kolimechkov S. Competitive bout model as a tool for estimation of female karateka specific endurance. European Journal of Physical Education and Sport Science. 2018;4(9):30-41.

12.Petrov L, Penov R, Kolimechkov S, Alexandrova A. Physiological and biochemical changes after a programmed kumite in male Shotokan karate practitioners. Archives of Budo Science of Martial Arts and Extreme Sports. 2018;14:171-8.

13. Tokyo 2020. Olympic sports - Karate 2019. [Internet]. 2019. [updated 2019; cited 2019 Nov 10]. Available from: https:// tokyo2020.org/en/games/sport/olympic/karate

14.IOC. IOC approves five new sports for Olympic Games Tokyo 2020 2016. [Internet]. 2019. [updated 2019; cited 2019 Nov 10]. Available from: https://www.olympic.org/news/iocapproves-five-new-sports-for-olympic-games-tokyo-2020

15.Schmidt RJ, Royer FM. Telemetered heart rates recorded during karate katas: a case study. Research quarterly. 1973;44(4):501-5. https://doi.org/10.1080/10671188.1973.10615231

16.Stricevic M, Okazaki T, Tanner AJ, Mazzarella N, Merola R. Cardiovascular Response to the Karate Kata. The Physician and sportsmedicine. 1980;8(3):57-67. https://doi.org/10.1080/00913847.1980.11948580
17.Shaw DK, Deutsch DT. Heart rate and oxygen uptake response to performance of karate kata. J Sports Med Phys Fitness. 1982;22(4):461-8.

18.Bussweiler J, Hartmann U. Energetics of basic karate kata. Europeanjournalofappliedphysiology.2012;112(12):3991-6. https://doi.org/10.1007/s00421-012-2383-z

19.WMA. WMA Declaration of Helsinki - Ethical Principles for Medical Research Involving Human Subjects. [Internet]. 2013. [updated 2019; cited 2019 Nov 10]. Available from: https://www.wma.net/policies-post/wma-declaration-ofhelsinki-ethical-principles-for-medical-research-involvinghuman-subjects/

20.Mateev H, Simova I, Katova T, Dimitrov N. Clinical evaluation of a mobile heart rhythm telemonitoring system. ISRN cardiology. 2012;2012:192670. https://doi.org/10.5402/2012/192670

21.Mukherjee S, Chia Yong Hwa M. Evaluation of The Lactate Pro Portable Blood Lactate Analyser Involving Multiple Tester approach. Asian Journal of Exercise \& Spores Science, 2006;3(1):55-60.

22.Koropanovski N, Berjan B, Bozic PR, Pazin N, Sanader A, Jovanovic S, et al. Anthropometric and physical performance profiles of elite karate kumite and kata competitors. Journal of human kinetics. 2011;30:107-14. https://doi.org/10.2478/v10078-011-0078-x

\section{Information about the authors:}

Penov R.; http://orcid.org/0000-0002-3355-0725; fighters.nsa@abv.bg; National Sports Academy; National Sports Academy 1700, Sofia, Bulgaria.

Petrov L.; http://orcid.org/0000-0003-1209-959X; dr.lubomir.petrov@gmail.com; National Sports Academy; National Sports Academy 1700, Sofia, Bulgaria.

Kolimechkov S.; (Corresponding author); http://orcid.org/0000-0003-0112-2387; dr.stefan.kolimechkov@gmail.com; STK Sport; 2 The Broadway, N9 0TR, London, United Kingdom.

Cite this article as:

Penov R, Petrov L, Kolimechkov S. Changes in heart rate and blood lactate concentration during karate kata competition.

Pedagogy of physical culture and sports, 2020;24(3):137-142.

https://doi.org/10.15561/26649837.2020.0306

This is an Open Access article distributed under the terms of the Creative Commons Attribution License, which permits unrestricted use, distribution, and reproduction in any medium, provided the original work is properly cited (http://creativecommons.org/licenses/by/4.0/deed.en).

Received: 02.12.2019

Accepted: 30.12.2019; Published: 05.01.2020 